\title{
PENGEMBANGAN LKPD BERBASIS SIMAS ERIC (SKIMMING, MIND MAPPING, QUESTIONG, EXPLORING, WRITING, COMMUNICATING) PADA POKOK BAHASAN KOLOID
}

\author{
Pertiwi Dwi Wahyuni Silaban ${ }^{1^{*}}$, Susilawati ${ }^{2}$, R Usman Rery ${ }^{3}$ \\ ${ }^{123}$ Pendidikan Kimia, Universitas Riau \\ *Email: Pertiwisilaban97@gmail.com
}

\begin{abstract}
Abstrak
Peserta didik sudah menggunakan LKPD di sekolah namun masih terlihat pasif dan kurang bisa menemukan konsep pembelajaran secara mandiri. Kurikulum 2013 menuntun peserta didik agar lebih aktif dan kreatif. Penelitian ini bertujuan untuk mengembangkan bahan ajar kimia seperti LKPD berbasis Simas Eric pada pokok bahasan koloid, mengetahui kevalidan LKPD berdasarkan aspek kelayakan isi, karakteristik Simas Eric, aspek kebahasaan, aspek penyajian, aspek kegrafisan dan mengetahui respon pengguna terhadap LKPD berbasis Simas Eric pada materi koloid. Penelitian pengembangan ini merupakan jenis Research and Development (R\&D) mengacu pada model 4-D. Objek penelitian ini adalah bahan ajar LKPD berbasis Simas Eric. Adapun instrumen pengumpulan data berupa lembar validasi yang diberikan kepada tiga validator. Setelah dilakukan revisi sebanyak dua kali diperoleh hasil validitas berturut-turut sebesar 95\% pada aspek kelayakan isi, 95,85\% karakteristik Simas Eric, 96,68\% pada aspek kebahasaan, 94,47\% pada aspek penyajian dan 91,68\% pada aspek kegrafisan, sehingga diperoleh skor rata-rata $94,47 \%$ kategori valid. LKPD yang dinyatakan valid oleh validator dilakukan uji satu-satu kepada 3 orang peserta didik yang sudah mempelajari materi koloid. Selanjutnya meminta respon kepada 3 orang guru kimia yang berbeda dan 20 peserta didik yang telah mempelajari materi koloid terhadap LKPD yang dikembangkan. Hasil respon guru diperoleh sebesar $88,23 \%$ termasuk kriteria sangat tinggi dan hasil respon peserta didik sebesar $82,5 \%$ termasuk kriteria sangat tinggi. Dengan demikian berdasarkan hasil analisis data disimpulkan bahwa LKPD berbasis Simas Eric dinyatakan valid dan dapat digunakan saat pembelajaran kimia SMA pada materi koloid.
\end{abstract}

Kata-kata kunci : Koloid, Simas Eric, LKPD.

\begin{abstract}
Students have used student worksheets in school, but they still look passive and cannot find the concept of independent learning. The 2013 curriculum guides students to be more active and creative. This study aims to develop chemistry teaching materials such as Simas Eric-based student worksheets on colloids, knowing the validity of student worksheets based on the feasibility of content aspects, Eric Simas characteristics, linguistic aspects, presentation aspects, graphics aspects and know the reactions of users on Simas Eric-based student worksheet on colloid material. This development research is a type of Research and Development $(R \& D)$ that refers to the 4-D model. The aim of this research is the Simas Ericbased Student Worksheet teaching material. The data collection tool in the form of a validation sheet has been handed over to three validators. After two revisions, the validity results were 95\% in the content feasibility aspect, $95.85 \%$ in the Simas Eric feature, $96.68 \%$ in the linguistic aspect, $94.47 \%$ in the presentation aspect and $91.68 \%$ in the aspect of graphics, so that the average score achieved is $94.47 \%$ valid category. Student worksheets that have been validated by the validator are tested one by one on 3 students who have studied colloid material. Then ask for answers from 3 different chemistry teachers and 20 students who have studied colloid material on the developed student worksheets. The teacher response results were $88.23 \%$ including very high criteria and the student response results of $82.5 \%$ including very high criteria. Thus, based on the results of the data analysis, it was concluded that the Eric Simasbased student worksheet was validated and could be used during high school chemistry on colloid material.
\end{abstract}

Keywords : Colloids, Simas Eric, student worksheet. 


\section{Pendahuluan}

. Pembelajaran merupakan proses interaksi antara guru dengan peserta didik untuk menumbuhkan pemahaman, kreativitas, keaktifan, daya pikir, potensi dan minat (Retnowati,D, $d k k, 2012$ ). Saat ini pelaksanaan pembelajaran berdasarkan kurikulum 2013 diharapkan dapat mengalami perubahan dimana peserta didik diberikan peran aktif untuk membangun sendiri pengetahuannya, sedangkan guru harus bertindak sebagai fasilitator yang kreatif dalam mewujudkan proses pembelajaran yang bermakna bagi peserta didik salah satunya melalui pengembangan bahan ajar

Hasil wawancara dengan guru kimia SMA Cendana Pekanbaru diperoleh informasi bahwa guru sudah menggunakan LKPD pada beberapa materi pembelajaran kimia baik bersifat eksperimen maupun noneksperimen, salah satunya materi koloid. Namun pembuatan LKPD belum mencakup syarat-syarat yang harus dipenuhi meliputi syarat didaktik, syarat konstruksi, dan syarat teknis.

Solusi untuk mengatasi permasalahan tersebut adalah membangun proses pembelajaran yang melibatkan peserta didik secara aktif untuk memperoleh pengetahuan secara mandiri melalui pengembangan bahan ajar LKPD yang harus memenuhi syarat-syarat dalam pembuatannya. Dengan adanya pengembangan bahan ajar LKPD, guru dapat merancang sesuai dengan situasi dan kondisi kegiatan pembelajaran yang dihadapi karena guru lebih mengetahui dan mengenal bagaimana kebutuhan dan karakeristik peserta didik sehingga mengerti konsep materi yang akan dipelajari serta mampu mengimplementasikan ke dalam kehidupan sehari-hari. LKPD yang dikembangkan berbasis model yaitu Simas Eric terdiri dari enam langkah/tahapan seperti skimming, mind mapping, questioning, exploring, writing, communicating. Model ini berbasis kontruktivisme berpusat pada student centered, berfokus pada konsep serta memberi kesempatan kepada peserta didik untuk mengkontruk pengetahuan melalui pengalaman belajar (Darmawan, E, dkk, 2015)

Penelitian Wahyu, P, A, dkk, (2019) dengan judul validitas dan praktikalitas LKPD berbasis Simas Eric pada materi pengukuran dan vektor untuk kelas X SMA/MA didapatkan hasil uji validitas kelayakan bahan ajar 
sebesar 0,38 dengan kategori sangat tinggi/sangat valid, aspek model Simas Eric diperoleh sebesar 0,85 dengan kategori sangat tinggi/sangat valid. Sedangkan hasil uji praktikalitas oleh guru sebesar 0,81 termasuk kategori tinggi/praktis dan pada peserta didik diperoleh sebesar 0,79 termasuk kategori tinggi/praktis. Berdasarkan pemaparan di atas, peneliti sudah melakukan penelitian berupa "Pengembangan LKPD Berbasis Simas Eric (Skimming, Mind Mapping, Questioning, Exploring, Writing, Communicating) Pada Pokok Bahasan Koloid."

\section{Metode Penelitian}

Penelitian telah dilaksanakan di Program Studi Pendidikan Kimia FKIP Universitas Riau Pekanbaru dengan uji coba satu-satu di SMA Negeri 5 Mandau dan respon peserta didik di SMA Cendana Pekanbaru. Pengembangan LKPD berbasis Simas Eric (Skimming, Mind Mapping, Questioning, Exploring, Writing, Communicating) pada pokok bahasan koloid menggunakan model pengembangan 4-D terdiri dari empat tahap/langkah yaitu Define (Pendefenisian), Design (Perancangan), Develop (Pengembangan) dan Disseminate (Penyebaran) (Trianto, 2014). Namun tahap Disseminate tidak dilakukan pada penelitian ini dikarenakan tujuan dibatasi hingga dihasilkan produk LKPD yang valid berdasarkan aspek kelayakan isi, karakteristik Simas Eric, kebahasaan, penyajian dan kegrafisan. 


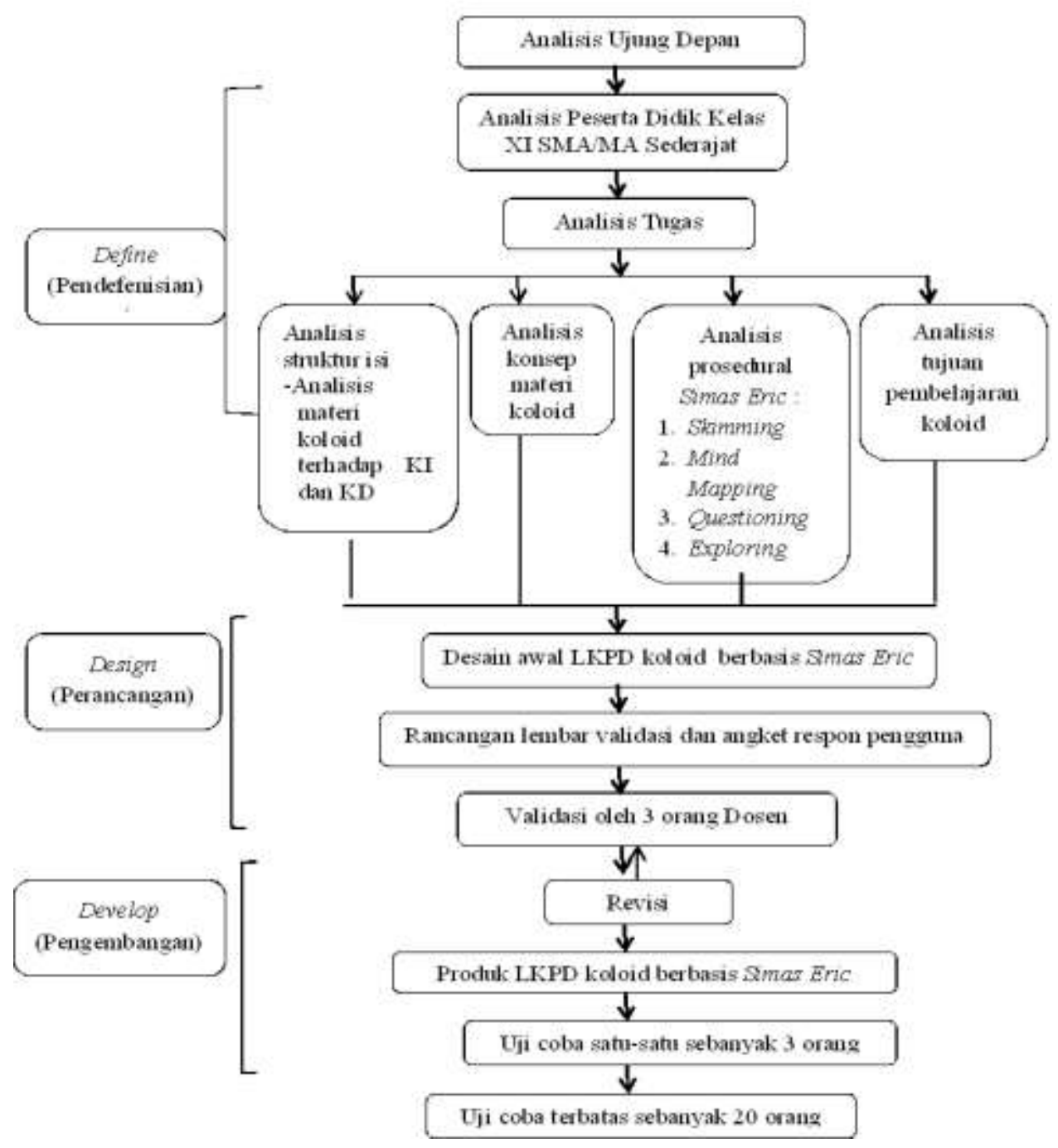

Gambar 1. Alur Pengembangan LKPD berbasis Simas Eric pada pokok bahasan koloid dengan model 4-D (modifikasi Trianto, 2014)

Teknik analisis data yang digunakan dalam penelitian pengembangan LKPD berbasis Simas Eric pada pokok bahasan koloid adalah analisis validitas dan respon pengguna. Pengumpulan data diperoleh pada tahap pengembangan diantaranya sebagai berikut :

1. Validasi

2. Revisi

3. Menyebarkan angket respon pengguna terhadap LKPD yang telah dikembangkan.

Adapun instrumen penelitian berupa : 
1. Lembar validasi oleh 3 orang validator yaitu dosen.

2. Uji coba satu-satu kepada 3 orang peserta didik yang sudah mempelajari materi koloid, serta

3. Angket respon pengguna yang terdiri dari 3 orang guru kimia yang berbeda dan 20 orang peserta didik yang sudah mempelajari materi koloid.

Data yang telah dikumpulkan kemudian dianalisis dengan teknik analisis tertentu. Adapun analisis validitas menurut Riduan (2012) yaitu sebagai berikut:

$$
\text { Persentase }=\frac{\text { Skor yang diperoleh }}{\text { Skor maksimum }} \times 100 \%
$$

Persentase yang diperoleh kemudian dikonversi menjadi nilai kualitatif dengan kriteria validitas pada Tabel I.

Tabel I. Persentase Tingkat Kevalidan Produk

\begin{tabular}{cc} 
Persentase (\%) & Keterangan \\
\hline $80-100$ & Valid \\
\hline $60,00-79,99$ & Cukup valid \\
\hline $50,00-59,00$ & Kurang valid \\
\hline $0-49,99$ & Tidak baik (diganti)
\end{tabular}

Analisis respon pengguna menggunakan skala Likert dengan penskoran yang disajikan pada Tabel II.

Tabel II. Penskoran Respon Pengguna

\begin{tabular}{cc} 
Skor & Keterangan \\
\hline 4 & Sangat Setuju (SS) \\
\hline 3 & Setuju (S) \\
\hline 2 & Kurang Setuju (KS) \\
\hline 1 & Tidak Setuju (TS)
\end{tabular}

(Sugiyono, 2017).

Persentase yang diperoleh kemudian dikonversi menjadi nilai kualitatif dengan kriteria yang disajikan pada Tabel III. 
Tabel III. Kriteria Respon Pengguna

\begin{tabular}{cc} 
Persentase (\%) & Kriteria Respon Pengguna \\
\hline $80,1-100$ & Sangat Tinggi \\
\hline $60,1-80$ & Tinggi \\
\hline $40,1-60$ & Sedang \\
\hline $20,1-40$ & Rendah
\end{tabular}

\section{Hasil Dan Pembahasan}

Penelitian pengembangan telah dilakukan menghasilkan suatu produk LKPD berbasis Simas Eric (Skimming, Mind Mapping, Questioning, Exploring, Writing, Communicating) pada pokok bahasan koloid. LKPD yang telah dikembangkan dapat digunakan saat proses pembelajaran. Pemaparan hasil dan pembahasan dari setiap langkah/tahapan 4-D yang telah dilakukan diuraikan sebagai berikut

\section{Tahap Pendefenisian (Define)}

- Analisis Ujung Depan

Analisis ujung depan telah dilakukan melalui telaah berbagai literatur yang relevan di SMA Cendana Pekanbaru melalui wawancara dengan guru kimia. Adapun informasi yang diperoleh bahwa guru sudah menggunakan LKPD saat proses pembelajaran pada beberapa materi kimia seperti koloid yang dipelajari peserta didik kelas XI SMA/MA semester genap. Namun, syaratsyarat penulisan LKPD yang dibuat oleh guru belum terpenuhi seperti syarat didaktik, kontruksi dan teknis. Selain itu koloid merupakan materi yang butuh pemahaman konsep, tetapi kebanyakan peserta didik lebih memilih menghafal sehingga tidak terciptanya kebermaknaan pembelajaran.

- Analisis Peserta Didik

Analisis peserta didik bertujuan untuk menganalisis karakteristik seperti perkembangan kognitif dan kemampuan dasar kimia. Peserta didik pada usia 16-17 tahun mempelajari materi koloid saat kelas XI SMA/MA dan berdasarkan teori perkembangan kognitif Piaget, mereka sudah bisa menalar secara logis ide-ide yang bersifat abstrak dan objek yang besifat konkrit. Namun, karena kurangnya pengalaman sehingga pengetahuan dan kecakapan yang dimiliki tidak dapat dimanfaatkan secara optimal. Padahal 
dengan banyaknya pengalaman banyak juga yang dapat dipelajari, tetapi peserta didik kadang mengalami kesulitan dalam memahami konsep-konsep abstrak.

- Analisis Tugas

Analisis tugas terdiri dari :

Pertama, Analisis struktur isi yaitu menganalisis kurikulum terhadap Kompetensi Isi (KI), dan Kompetensi Dasar (KD) terkait materi yang akan dikembangkan yaitu materi koloid kelas XI SMA/MA semester genap. Kedua, analisis konsep yaitu mengidentifikasi konsep-konsep utama materi koloid sesuai dengan kurikulum 2013 pada KD 3.14 dan 4.14 yang akan diajarkan serta disusun secara sistematis dalam bentuk peta konsep. Ketiga, analisis prosedural yaitu tahap/langkah untuk menyelesaikan tugas dan menemukan konsep yang digunakan pada LKPD berbasis Simas Eric terdiri dari Skimming, Mind Mapping, Questioning, Exploring, Writing, Communicating. Keempat, analisis tujuan yaitu menghasilkan suatu tujuan pembelajaran dan IPK yang harus dicapai peserta didik dan telah dirumuskan berdasarkan Kompetensi Dasar (KD 3.14 dan 4.14).

\section{Tahap Perancangan (Design)}

LKPD yang dirancang peneliti mencakup kriteria kelayakan meliputi syarat didaktis, kontruksi dan teknis. Rancangan awal LKPD terdiri dari: a).Judul, b).Petunjuk belajar, c).Tujuan pembelajaran, d).Kompetensi Dasar, e).Indikator pencapaian kompetensi, f).Materi singkat, g).Kegiatan LKPD, h).Kolom penilaian, i).Daftar pustaka. Sedangkan desain instrumen berupa kisi-kisi lembar validasi serta angket respon pengguna (guru dan peserta didik).

\section{Tahap Pengembangan (Develop)}

- Validasi LKPD

Validasi dilakukan bertujuan untuk memperoleh penilaian dan saran oleh tim validator terhadap LKPD berbasis Simas Eric pada pokok bahasan koloid. Pada penelitian ini validasi dilakukan sebanyak dua kali oleh masing-masing validator. Berikut Identitas masing-masing validator : 
1. Dr. Susilawati, M.Si dosen program studi pendidikan kimia Universitas Riau

2. Dr. H.R. Usman Rery, MPd dosen program studi pendidikan kimia Universitas Riau

3. Dr. Ericka Darmawan,S.Si.,S.Pd.,M.Pd dosen program studi pendidikan biologi Universitas Tidar

Adapun hasil analisis merupakan validasi kedua berdasarkan aspek kelayakan isi, karakteristik Simas Eric, aspek kebahasaan, aspek penyajian dan aspek kegrafisan. Berikut tabel persentase skor validasi dari berbagai aspek oleh tim validator disajikan pada Tabel IV.

Tabel IV. Persentase Skor Oleh Validator

\begin{tabular}{cccc} 
No & Aspek Penilaian & Persentase (\%) & Kategori \\
\hline 1 & Kelayakan isi & 95 & Valid \\
\hline 2 & Kelayakan Simas & 95,85 & Valid \\
& Eric & & Valid \\
\hline 3 & $\begin{array}{c}\text { Kelayakan } \\
\text { kebahasaan }\end{array}$ & 96,68 & Vald \\
& $\begin{array}{l}\text { Kelayakan } \\
\text { penyajian }\end{array}$ & 94,47 & \\
\hline 5 & $\begin{array}{l}\text { Kelayakan } \\
\text { kegrafisan }\end{array}$ & 91,68 & Valid \\
& & &
\end{tabular}

Setelah LKPD selesai divalidasi oleh tim validator dan direvisi oleh peneliti, maka dilakukan uji coba satu-satu kepada 3 orang peserta didik yang sudah mempelajari materi koloid dengan kemampuan kompetensi berbeda untuk mengerjakan LKPD yang telah dinyatakan valid oleh validator. 3 orang peserta didik tersebut tidak ada yang memberi pertanyaan, namun 2 orang peserta didik memberi saran yaitu supaya memperhatikan ukuran tempat jawaban dan tabel hasil pengamatan percobaan 2 pada LKPD 4 serta lebih hati-hati saat memprint agar lembar exploringnya tidak berlebih. Selanjutnya meminta respon kepada 3 orang guru kimia yang berbeda sekolah dan kepada 20 orang peserta didik yang sudah mempelajari materi koloid terhadap LKPD yang telah 
dikembangkan. Berikut disajikan ke dalam tabel hasil yang diperoleh dari masing-masing respon pengguna yaitu :

Tabel V. Hasil Persentase Respon Pengquna

\begin{tabular}{cccc} 
No & Responden & Persentase (\%) & $\begin{array}{c}\text { Kriteria Respon } \\
\text { Pengguna }\end{array}$ \\
\hline 1 & Guru & 88,23 & Sangat tinggi \\
\hline 2 & Peserta didik & 82,5 & Sangat tinggi \\
\hline
\end{tabular}

Berdasarkan respon tersebut maka diperoleh LKPD berbasis Simas Eric (Skimming, Mind Mapping, Questiong, Exploring, Writing, Communicating) pada pokok bahasan koloid yang final. Hal ini didukung dari hasil penelitian (Darmawan, E, dkk, 2015) yaitu Pengembangan Model Pembelajaran Simas Eric Menggunkaan Learning Development Cycle memperoleh kategori sangat layak terhadap kelayakan model Simas Eric dan termasuk kategori sangat tinggi keparktisan validasi oleh guru.

Penelitian selanjutnya didukung oleh (Wahyu, P, A, dkk, 2019) yaitu validitas dan praktikalitas LKPD berbasis Simas Eric pada materi pengukuran dan vektor kelas X SMA/MA diperoleh hasil uji kelayakan bahan ajar sebesar 0,83 kategori sangat tinggi/sangat valid dan aspek model Simas Eric sebesar 0,85 termasuk kategori snagat tinggi/sangat valid. Sedangkan hasil uji praktikalitas diperoleh rata-rata sebesar 0,81 oleh guru termasuk kategori tinggi/praktis dan sebesar 0,79 oleh peserta didik juga termasuk kategori tinggi/praktis.

\section{Kesimpulan}

LKPD berbasis Simas Eric pada pokok bahasan koloid telah dinyatakan valid oleh ketiga tim validator yang berdasarkan aspek kelayakan isi $95 \%$, aspek karakteristik Simas Eric 95,85\%, aspek kebahasaan 96,68\%, aspek penyajian $94,47 \%$ dan aspek kegrafisan $91,68 \%$, sehingga diperoleh rata-rata sebesar $94,76 \%$. Respon pengguna yaitu guru diperoleh persentase $88,23 \%$ dan peserta didik dengan persentase $82,5 \%$, hasil dari kedua respon pengguna 
tersebut berada pada kriteria sangat tinggi. Dengan demikian LKPD yang telah dihasilkan ini dapat digunakan dalam proses pembelajaran kimia materi koloid.

\section{Daftar Referensi}

Arikunto, S. 2008. Prosedur Penelitian Suatu Pendekatan Praktek. Rineka Cipta. Jakarta.

Darmawan, E. S, Zubaidah. H, Susilo. H, Suwino. 2015. 2015. Pengembangan Model Pembelajaran Simas Eric (Skimming, Mind Mapping, Questioning, Exploring, Writing, Communicating) Menggunakan Learning Development Cycle. Prosiding Seminar Nasional pendidikan Biologi. Universitas Negeri Malang : 694-709

Retnowati, D. Siadi, K. Harjito. 2012. Penerapan Metode Pembelajaran Kuantum Dengan Pendekatan Kimia Hijau Pada Materi Redoks. Jurnal FMIPA Universitas Negeri Semarang. 1(1).

Riduan. 2012. Skala Pengukuran Variabel-variabel Penelitian. Alfabeta. Bandung.

Sugiyono. 2017. Memahami Penelitian Kualitatif. Alfabeta. Bandung.

Trianto. 2014. Model Pembelajaran Terpadu Konsep Strategi dan Implementasinya dalam KTSP. Bumi Aksara. Jakarta.

Wahyu, P, A. A, Putra. H. F, Mufit. 2019. Validitas dan Praktikalitas LKPD Berbasis Simas Eric Pada Materi Pengukuran dan Vektor Untuk Kelas X SMA/MA. Jurnal Pendidikan Fisika 3(12) 